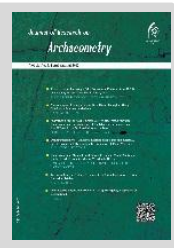

\title{
Using Hard-Shell Molding in Restoration and Reconstruction of Capitals of Sadaghiani House of Tabriz in Order to Conserve and Promote the Quality of the Original Specimen's Formal Details
}

\author{
Ebrahim Imani* \\ Lecturer, Islamic Design Faculty, Tabriz Islamic Art University, Tabriz, IRAN
}

Special potentials of plaster, including low price comparing to other materials, optimal resistance to environmental conditions, fast hardening, ductility and good paintability, make it one of the most used materials in Iranian architecture during the various historical periods. These features results in using the plasters as the main material in the interior decoration of monuments in most historical periods. On the other hand, easy ductility and fast hardening encourage the Iranian architects to use plaster in the various façade decorations of monuments. However, vulnerability to moisture and rapid climate changes in the mountainous regions reduce the life expectancy of plaster, where it becomes vulnerable in the exterior decorations of monuments. These drawbacks make the restoration and reconstruction of exterior facade adornments of historical monuments to be established in the shortterm periods. The complex of Sadaghiani House of Tabriz is one of the monuments adapted on List of National Sites by No. 7498 on February 1, 2003. The house has plenty of plaster works in decoration of monument facade and capitals. This complex was built in mid of Qajar Era and a vast section of house had been demolished for different reasons, where the plaster capitals had also been fully damaged. Following the retrofitting, the restoration of complex commenced in 2012 submitting to Tabriz Islamic Art University. After reconstruction of various sections of monument and as a practical examples of plaster artworks restoration, some of the remaining capitals restored and reconstructed. These capitals possesses complex form elements and details, and consequently, their reconstruction is costly and time-consuming process. Hence, using alternative methods and the potential of techniques in relevant domains stands necessary. To duplicate the reconstructed capitals while maintaining the form features and structural details of samples, the method of hard-shell molding was employed which is appropriate for molding of artistic and industrial works that have complex form elements and negative spaces in their structure. This method entails a good robustness because of having a hard shell that is usually made of FRP polymer matrix composites. In casting, assembly and installing mold on the determined site and using a flexible core, usually made of silicon resin, reduce the number of mold pieces and creates form details and negative spaces with an optimum quality. In this regard, one of the remaining capitals with more complete form details was selected as the reference, then the stages of restoration implemented and, finally the stages of molding and duplication of original sample carried out. Using this method of molding and reconstruction of demolished samples causes the improvement in the quality, robustness, where the process of restoration and reconstruction has been briefly reported in the present report.

*Corresponding author: ib.imani@gmail.com 


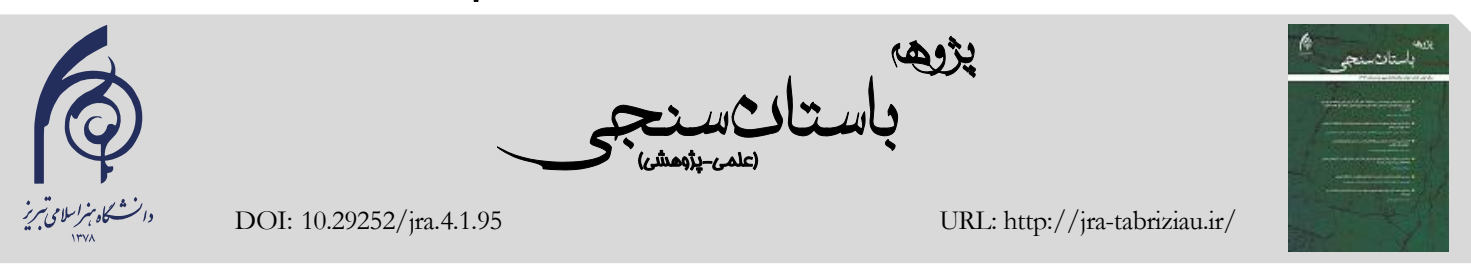

يادداشت فنى

(1)

استفاده از قالبكيرى دويوسته در مرمت و بازسازى

سرستونهاى خانه صدقيانى تبريز جهت حفظ و ارتقاء كيفيت دوبت

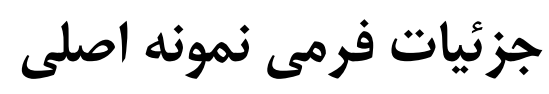

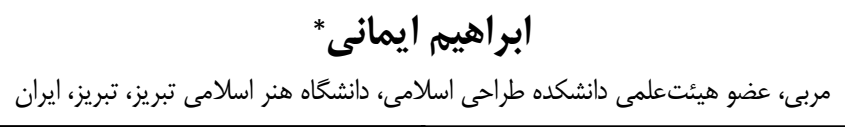

تاريخ يذيرش:

تاريخ دريافت:

تزيينـات بيرونسى بناهـاى تـاريخى در دورههـاى زمـانى

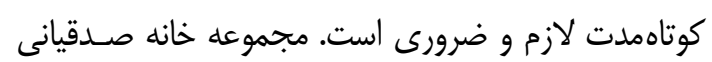

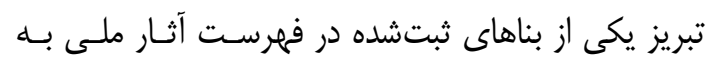

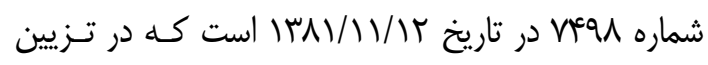

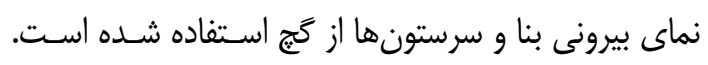

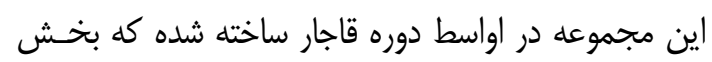

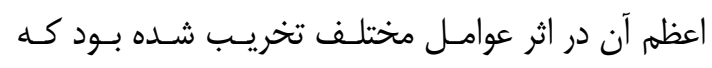

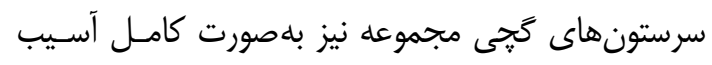

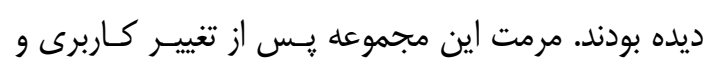

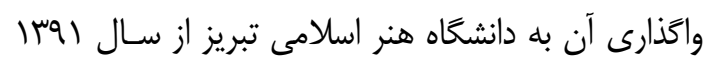

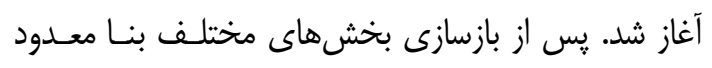

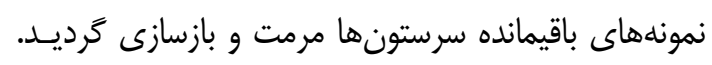

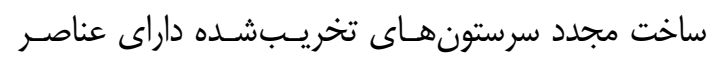

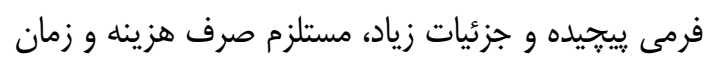

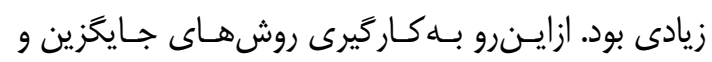

قابليتهاى ويزه كَج باعث كَرديده تا در معمارى ايـران در

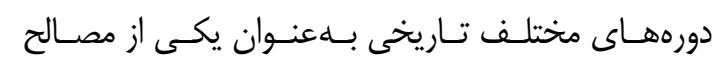

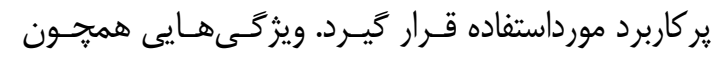

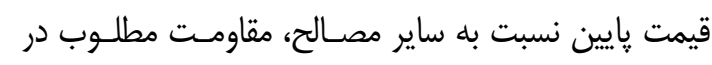

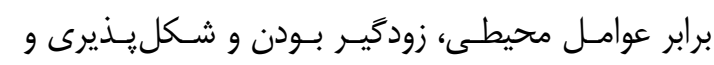

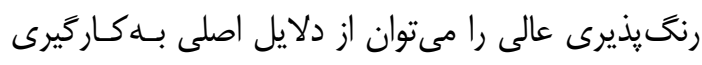

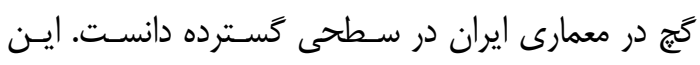

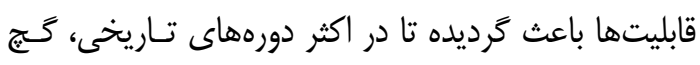
بلهعنوان ماده اصلى تزيينات داخلى بناها مورداستفاده قـرار

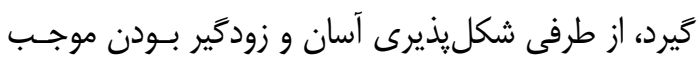

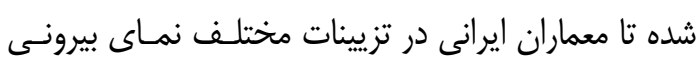

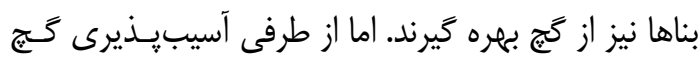
در مقابل رطوبت و تغييرات سريع آب و هوايى در منـاطق كانق

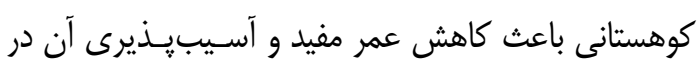

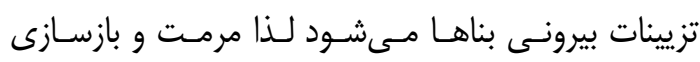

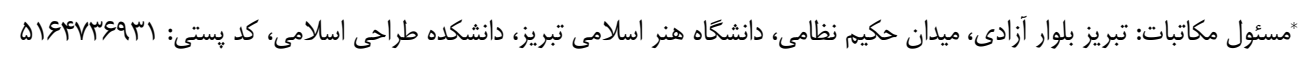

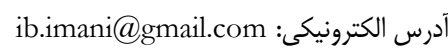
ج) حق نشر براى نويسنده(كان) بوده و نويسنده تحت مجوز Creative Commons Attribution License به مجله اين امكان ران امىدهد كه مقالـه

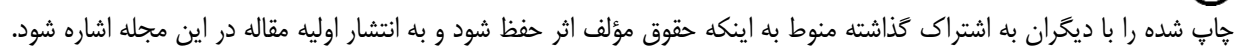


شهر تبريز كه مربوط به اواخر دوره صففوى و دوره قاجـار هستند، اين مسئله قابل مشاهده است. سرستونهاى خانــهـ

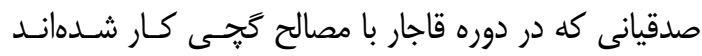
بلهمروزمان دهار فرسايش و آسيب شده كه جهت مرمـت

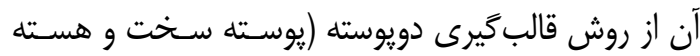
نرم) Hard-Shell Molding استفاده كرديد. خانه صدقيانى بلصورت مجموعهاى متشكل از جند

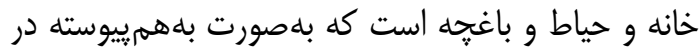

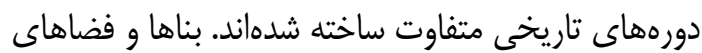

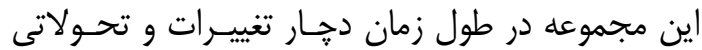

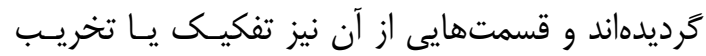

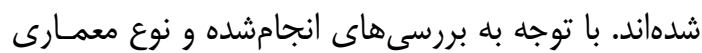
بنا مىتوان كفت كه اين خانه متعلق بــا اواسـط دورهى

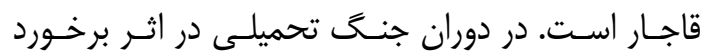

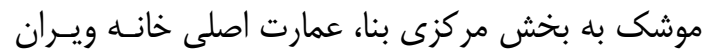

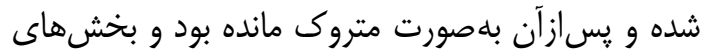

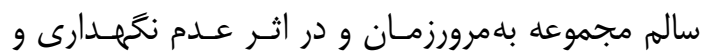

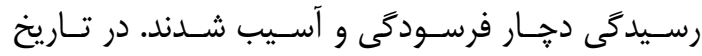

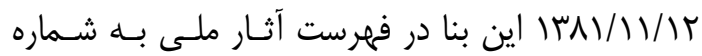

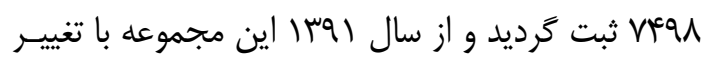

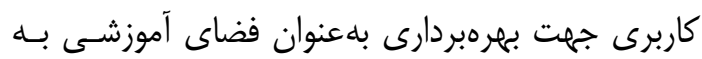

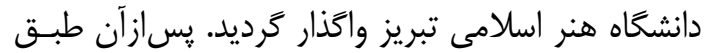

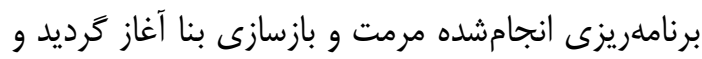
تا امروز ادامه دارد.

با توجه به نوع معمارى بنا و وجود ستونهاى متعـدد

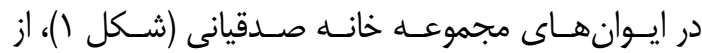
سرستونهاى گَّى براى زيبايى و تزيين بنا استفاده شــده

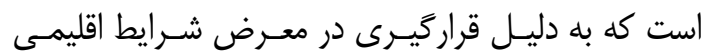

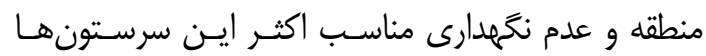

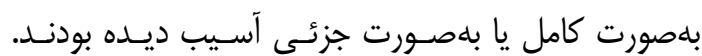
ييجيدگى عناصر فرمى و همجنـين موقعيـت قراركيـرى،

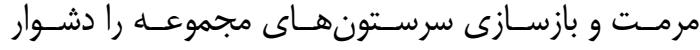
مى نمود. بر اين اسـاس تمـامى سرسـتونهـا، مرمـت يـاــا

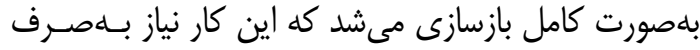

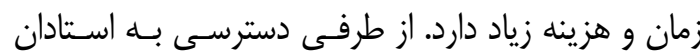

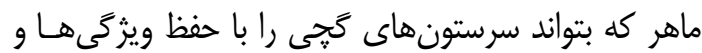
جزييات فرمى مربوط به دوره ساخت آن دشوار مسنمـود.
استفاده از يتانسيل شيوههاى مورداستفاده در حـوزهـاى

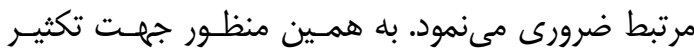

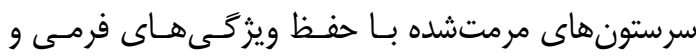

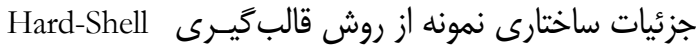

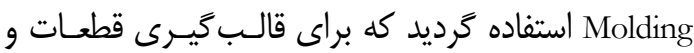

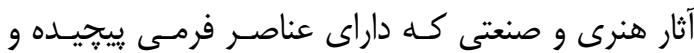

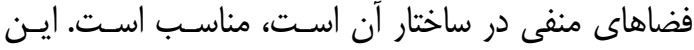
روش به دليل دارا بودن يوسته سخت كه معمـولاًا از مـواد

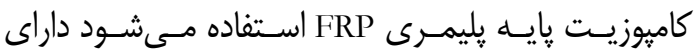
استحكام خوبى بوده در قالبريزى، مونتاز و نصب قالب بر

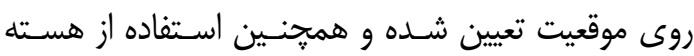
منعطف كه عموماً با رزين سيليكون ساخته مى شودو، تعـداد

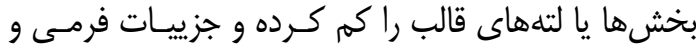

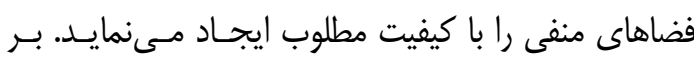

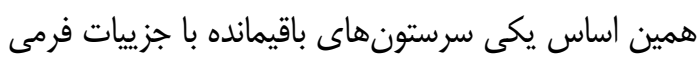
كاملتر انتخاب شد و مراحل مرمت و تكميلى بر روى آن اجرا و سيس مراحل قالب تيرى و تكثير نمونه اصلى انجام

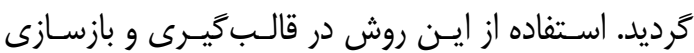
نمونههاى تخريبشده باعث ارتقــاء كيفيـت، اسـتحكام و و

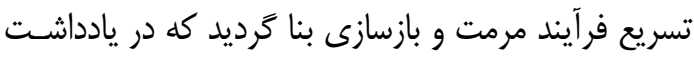
فعلى بلصورت خلاصه مراحل كار كزارش شده است. در دورههاى مختلف معمارى سنتى ايران، از مصـالح زيادى در تزيينات فضاى داخلى و فضـاى خـارجى بناهـا

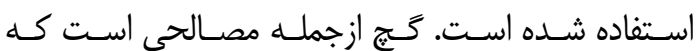

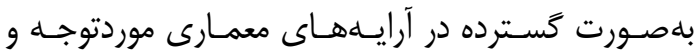

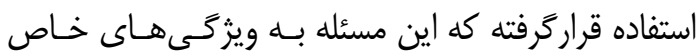

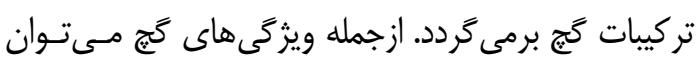

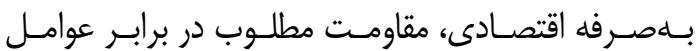

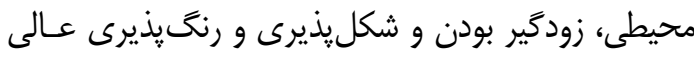

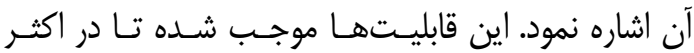
دورههاى تاريخى، گّ بلعنوان ماده اصلى تزيينات داخلى إنى

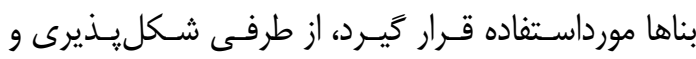
زودَير بودن باعث كرديده تا معماران ايرانسى در تزيينـات

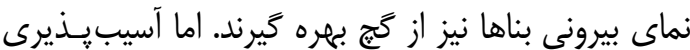

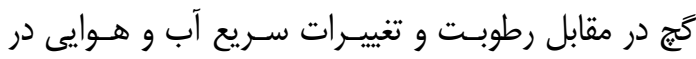
مناطق كوهستانى باعث كاهش عمر مفيد اين مـاده شــــ

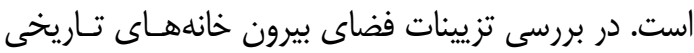

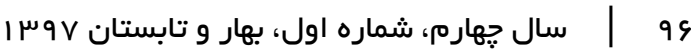



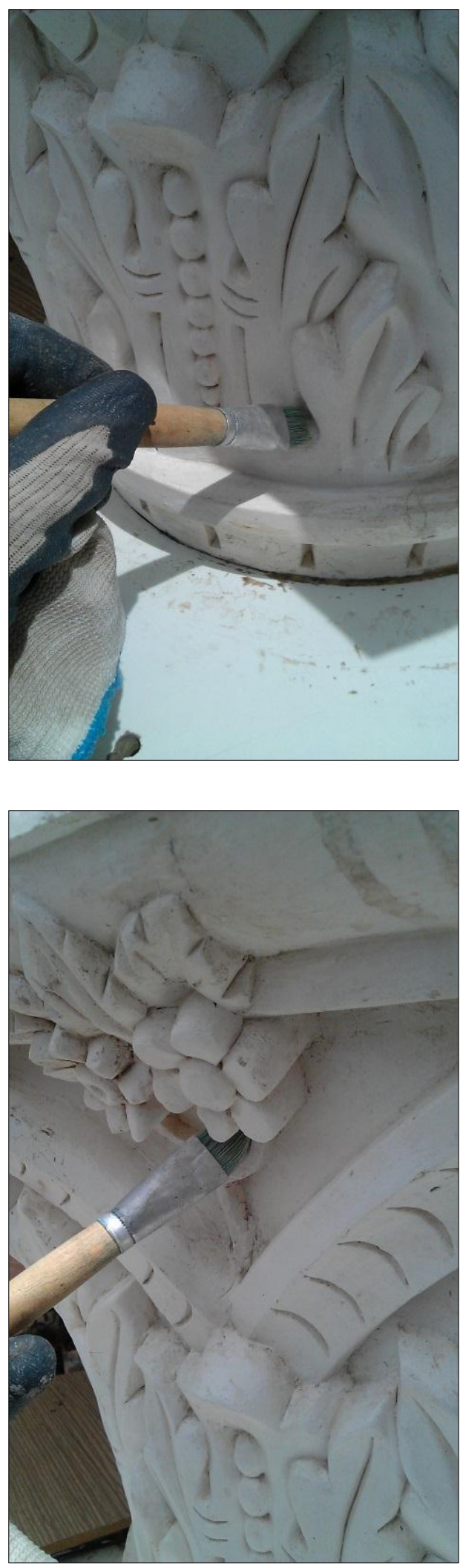

شكل ז: انجام مراحل مرمت و بازسازى نمونه اصلى سرستون گَّى انتخابشده

Fig. 2: Steps to perform the restoration and repair of the selected original Plaster Capital

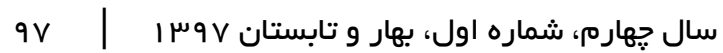

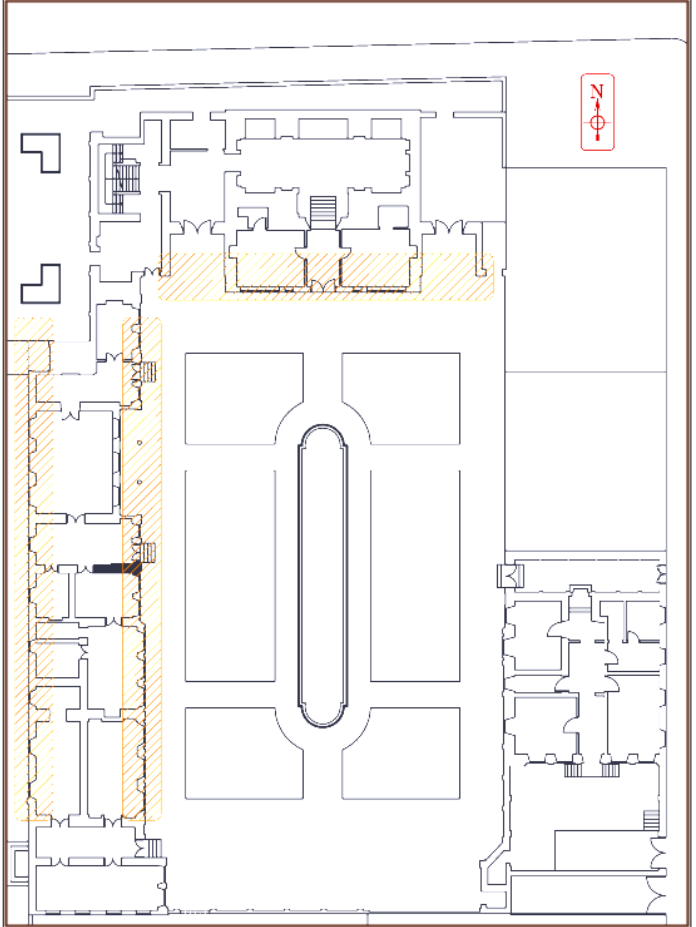

شكل ا: پيلان مجموعه خانه صدقيانى و موقعيت قرارگيرى ستونها Fig. 1: Plans for the Sadaghiani House complex and the columns location

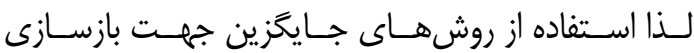
نمونههايى كه كاملاً تخريب شده بودند ضرورى بود. براى ساخت قطعات و نمونههاى هنرى و صنعتى بـاــا

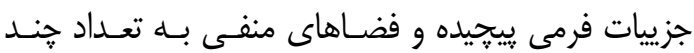

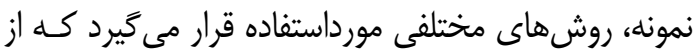

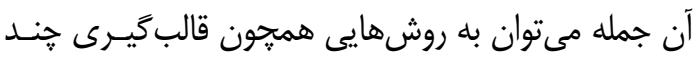

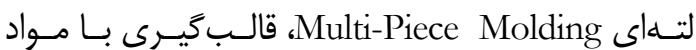
منعطـف Flexible Molding و قالـب

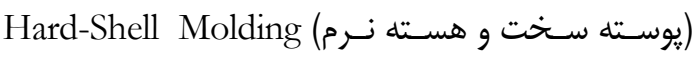
اشاره نمود. با در نظر گرفتن عواملى مانند؛ ابعاد، فرم، مواد

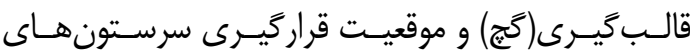

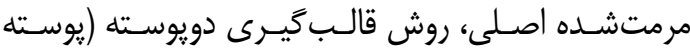

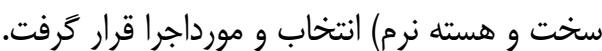
اين روش به دليل دارا بودن يوسته سخت كه معمولاً از مواد كامبوزيت بايسه بليمـرى FRP اسـتفاده مسىشـود داراى استحكام خوبى بوده در قالبريزى، مونتـاز و نصـب قالب بر رورى موقعيت تعيينشــده و همجنــين اسـتفاده از هسته منعطف كه عموماً با رزين سيليكون ساخته مىشودين 
ساخت هسته نرم سيليكونى با گـلـل آلفـا كلـى، س- ايجـاد

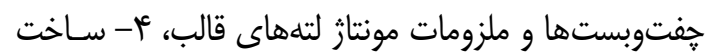

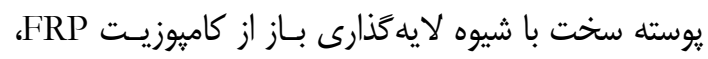

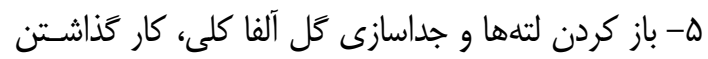

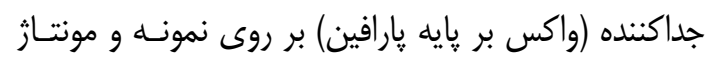

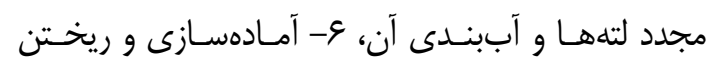
تركيب رزيـن سـيليكون، V- بـاز كـردن قالب و سـاخت بخشهاى ساختارى تكميلى، است كه در ادامه بهصـورت جدول ارائه گرديده است.
تعداد بخشها يا لتههـاى قالـب را كـم كـرده و جزييـات فرمسى و فضـاهاى منفـى را بــا كيفيـت مطلــوب ايجــاد

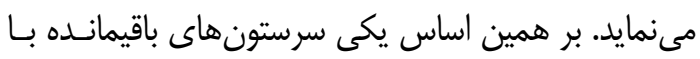

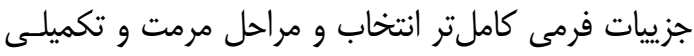

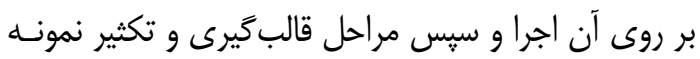
اصلى انجام گرديد.

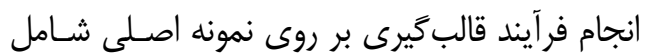

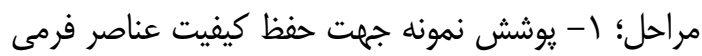

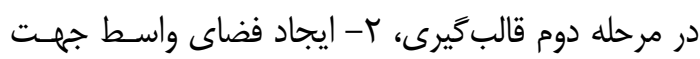

جدول ا: مراحل فرآيند ساخت قالب دويوسته بر روى نمونه اصلى سرستون گَجى

Table 1: Stages of the process of making the Hard-Shell Mold on the selected original Plaster Capital

\begin{tabular}{|c|c|c|c|c|}
\hline $\begin{array}{l}\text { تصوير } \\
\text { Image }\end{array}$ & $\begin{array}{c}\text { مواد ورشهاى } \\
\text { مورداستفاده } \\
\text { Materials and Methodes }\end{array}$ & $\begin{array}{c}\text { مواد قابلاستفاده } \\
\text { Usable Mterials }\end{array}$ & $\begin{array}{l}\text { شرح مرحله و فرآيند } \\
\text { Stage of Process }\end{array}$ & $\begin{array}{l}\text { رديف } \\
\text { No }\end{array}$ \\
\hline & 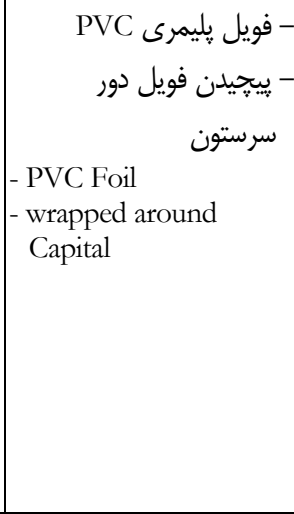 & $\begin{array}{l}\text { - فويل يا سلفونهاى يليمرى -PVP-PA-LDPE) } \\
\text { PVC-PA } \\
\text { - Plastic Foil (PP-PVC-PA- } \\
\text { LDPE) }\end{array}$ & 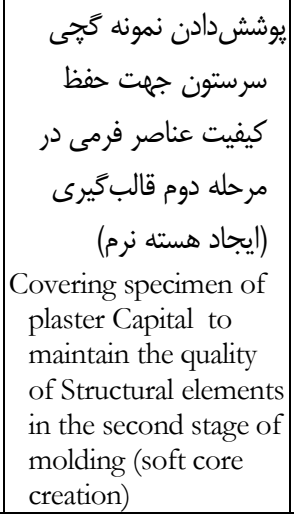 & 1 \\
\hline & 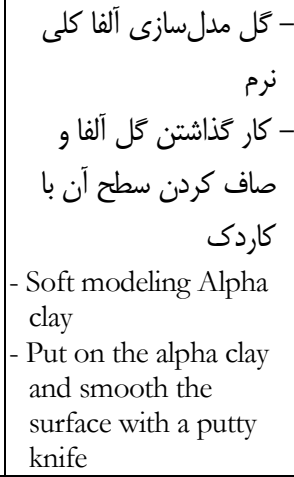 & 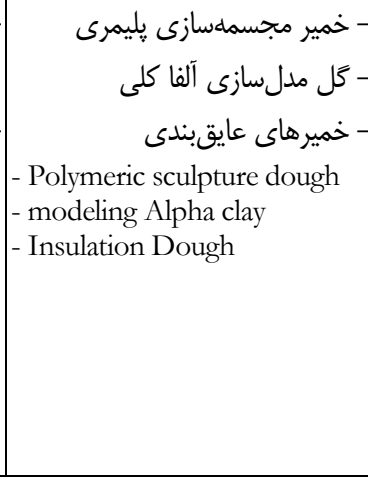 & 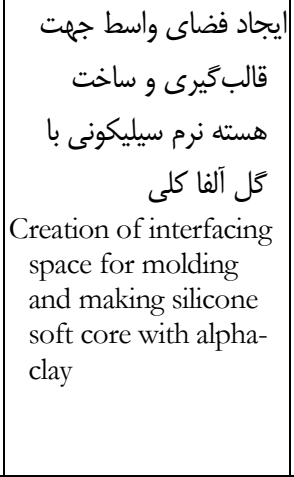 & 2 \\
\hline & 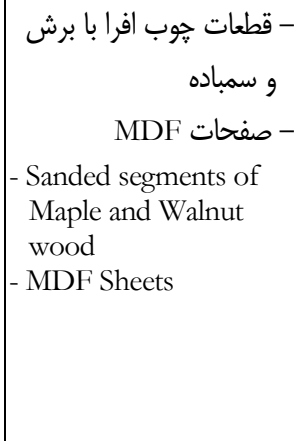 & 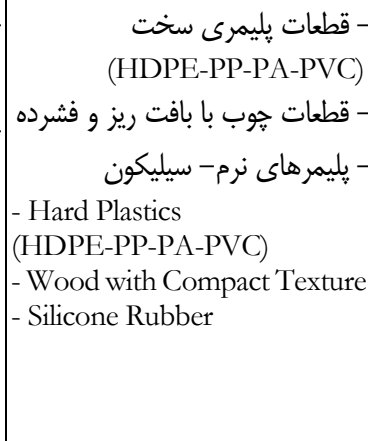 & |تعبيه شابلون، جفتوبستها & 3 \\
\hline
\end{tabular}




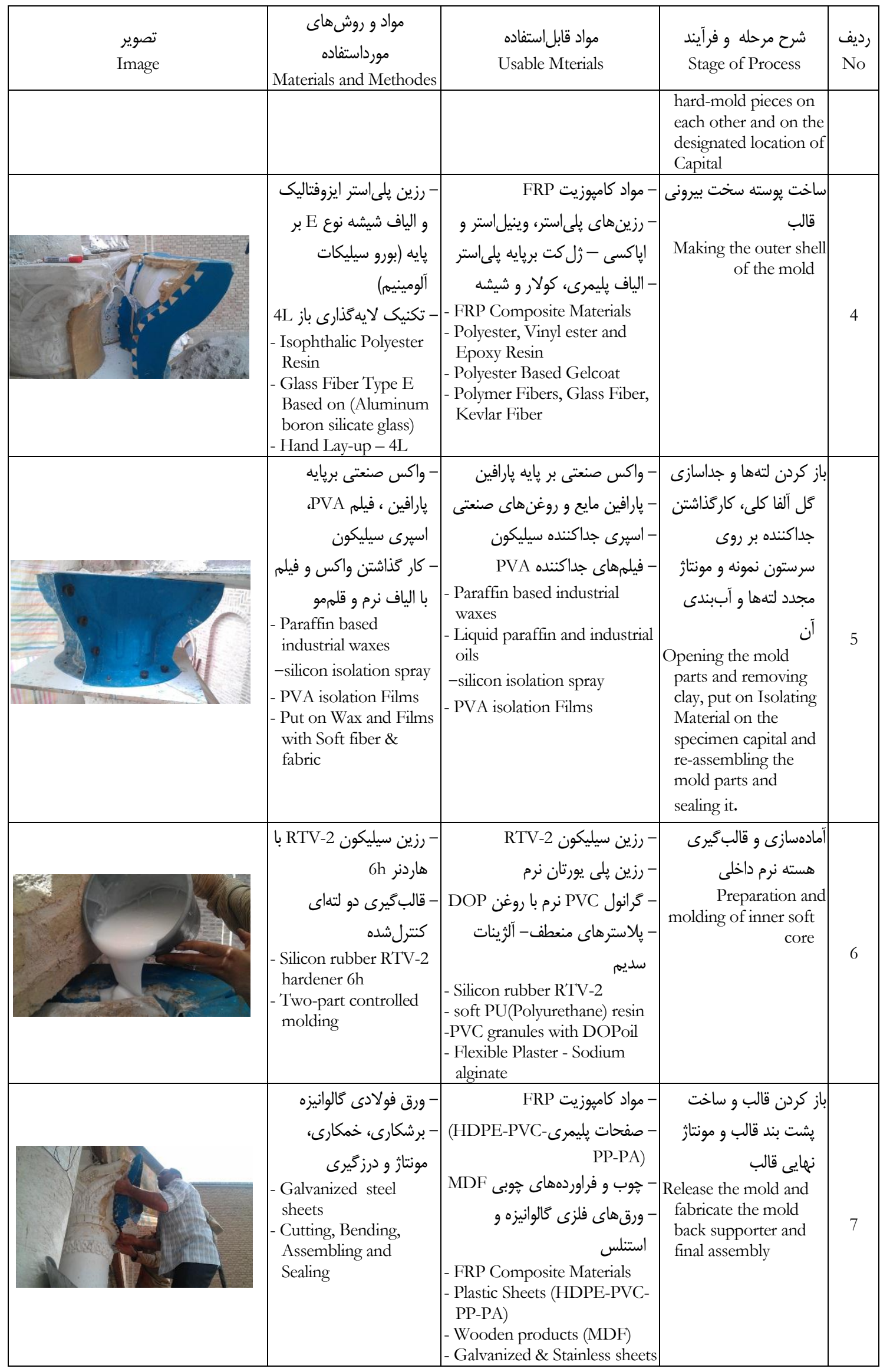


استحكام بيشترى نسبت به نمونههاى بازسازىشده با گَج

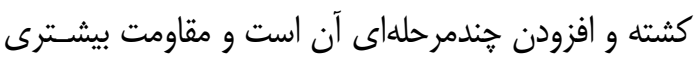

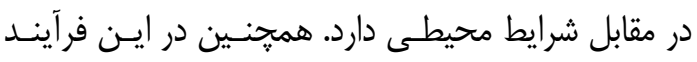

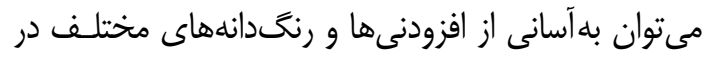
تركيب ملات كج استفاده نمود. به كاركيرى روش قالب ئيرى دويوسته(يوسته سـخت

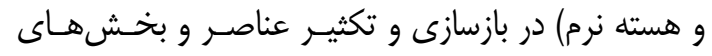

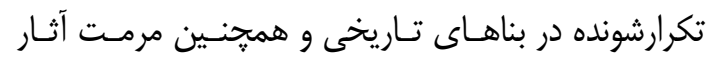

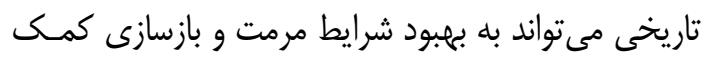

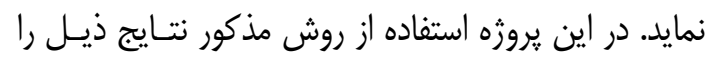

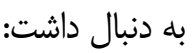

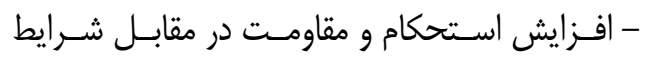

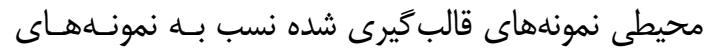
مشابه مرمتشده سرستون گَّهى

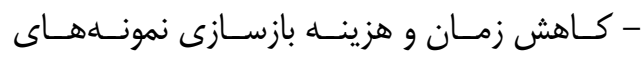
تخريبشده - حفظ كيفيت و ويثَى هـاى عناصـر فرمس نمونسه
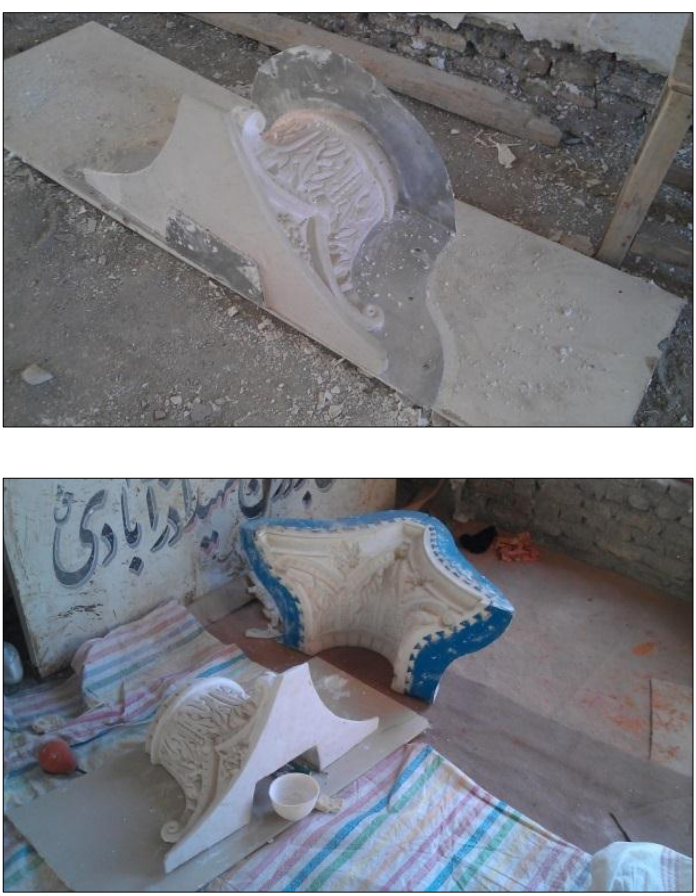
شكل س: نمونهسازى قطعات جديد با استفاده از قالب دويوسته Fig. 3: Prototyping of new parts using Hard-Shell Mold

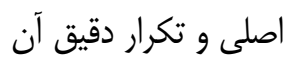

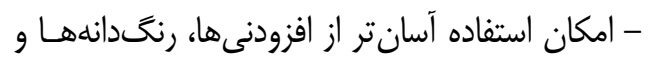

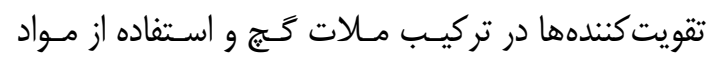
جايخزين گج در قالبكيرى در صورت لزوم درئن

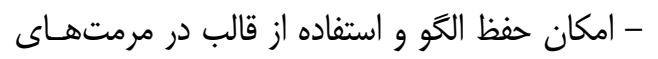
بعدى و يروزههاى مشابه. يس از ساخت و تكميل بخشهـاى مختلـف قالـب،

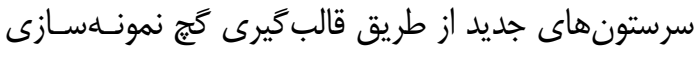

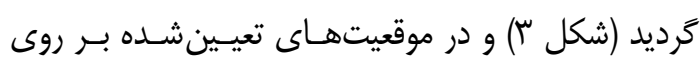

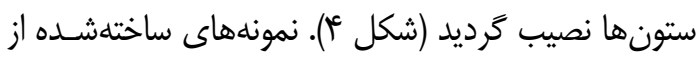

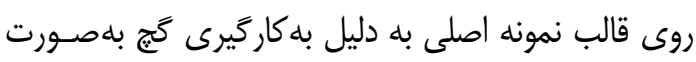

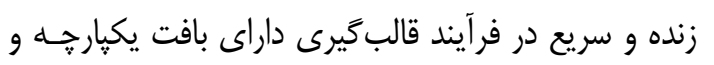

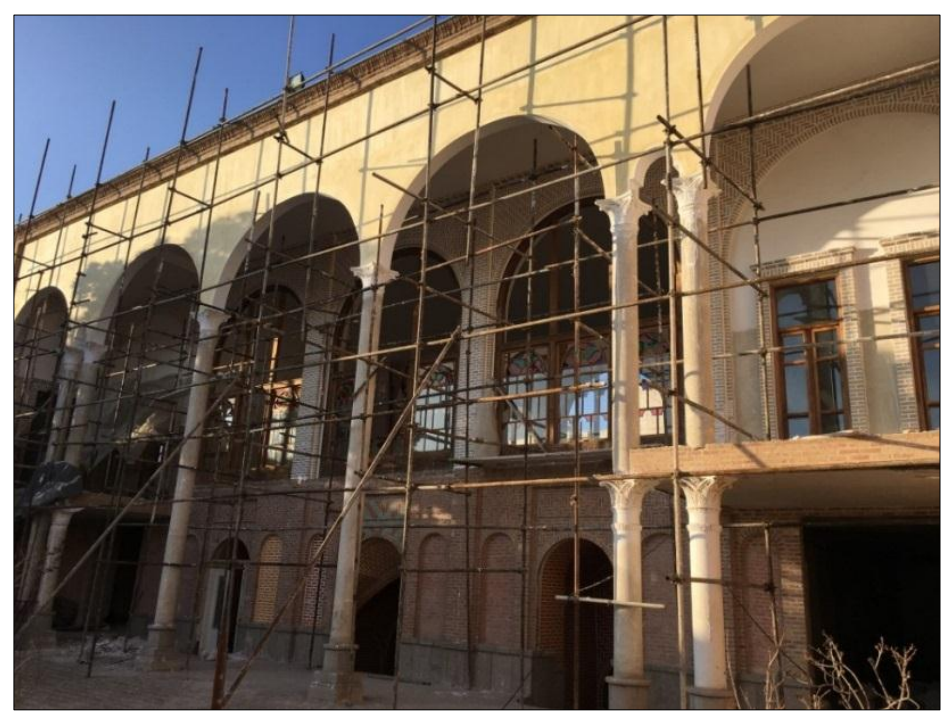

شكل ז: نصب نمونههاى قالب يرى شده در موقعيتهاى موردنظر

Fig. 3: Assembling molded samples in the intend positions 